\title{
Early Visible Improvements during K101-03 Treatment: An Open-Label Multicenter Clinical Investigation in Patients with Onychomycosis and/or Nail Psoriasis
}

\author{
Bianca Maria Piraccini $^{a} \quad$ Michela Starace $^{a}$ Anders Toft $^{b}$ \\ a Department of Experimental, Diagnostic and Specialty Medicine, Università di Bologna, Bologna, Italy; \\ ${ }^{b}$ Moberg Pharma AB, Bromma, Sweden
}

\section{Keywords}

Onychomycosis $\cdot$ Nail psoriasis $\cdot$ K101-03 $\cdot$ Topical treatment . Cosmetic improvements

\begin{abstract}
Introduction: Onychomycosis and nail psoriasis can be embarrassing to patients, so improving the appearance of affected nails should be one of the key short-term goals of treatment. Methods: An 8-week open-label multicenter study was conducted to assess whether K101-03, a marketed topical treatment containing propylene glycol, glycerol, urea, and lactic acid, could produce rapid cosmetic improvements in affected nails. Adult patients with a big toenail or thumbnail (the "target" nail) affected by onychomycosis ( $n=$ 72 ) or psoriasis $(n=34)$ or both $(n=1)$ applied K101-03 to their affected nails once a day for 8 weeks. During and after treatment, patients rated the overall appearance of their target nail on a 4-point scale. They also assessed whether thickening, discoloration, brittleness, and softness of the target nail had improved since baseline. Adverse events (AEs) that occurred between the first application of K101-03 and the end of treatment were recorded and categorized according to severity and relationship to K101-03. Results: After 8 weeks of K101-03 treatment, $92.2 \%$ of patients (95\% confi-
\end{abstract}

dence interval [CI] 87.06-97.40) reported at least some improvement in the target nail. After 1 week of treatment, $78.3 \%$ of patients with onychomycosis $(95 \% \mathrm{Cl} 68.53-87.99)$ reported at least some improvement in the target nail, and $55.1 \%$ of them reported that discoloration of their target nail had improved. Three patients reported a total of $5 \mathrm{AEs}$, none of which were judged to be related to K101-03. Conclusions: In summary, K101-03 was well tolerated in patients with onychomycosis or nail psoriasis and rapidly improved their nails.

(C) 2017 The Author(s)

Published by S. Karger AG, Basel

\section{Introduction}

While very different in terms of etiology, onychomycosis and psoriatic nail dystrophy both involve dystrophy of toenails and fingernails and cause embarrassment and discomfort to patients.

Onychomycosis is characterized by discoloration, detachment, and thickening of nails, which can become brittle with an irregular surface. It mainly occurs in older adults, and in Europe its prevalence has been estimated to be as high as $23 \%[1,2]$. Onychomycosis is not dangerous as such, but it does not resolve without treatment, can be 
transmitted from nail to nail and even between individuals [3], and negatively affects quality of life in long-term sufferers [4]. Curing the causative infection is a challenge. Existing treatment options include a range of antifungal agents, but their use is associated with fundamental disadvantages. These include unpleasant side effects in the case of oral treatments [5] and inadequate efficacy for antifungals applied directly to affected nails $[6,7]$. Moreover, successful treatment can take up to 1 year, and recurrence is common [8].

Psoriatic nail dystrophy (or nail psoriasis) has been estimated to occur at some point in up to $90 \%$ of patients with psoriasis [9] and may also occur as an isolated finding not associated with skin lesions. It often causes cosmetic problems and functional impairment, and may also be painful [10]. In a Dutch survey of 1,728 patients with nail psoriasis, $52 \%$ of the participants suffered from pain as a result of their disease, and many participants experienced impairment in their professional and private lives [11]. Like onychomycosis, nail psoriasis can be difficult to treat, with poor penetration of topical treatments into the nail, pain associated with intralesional therapies, and side effects of systemic drugs limiting the usefulness of current treatments [9].

Onychomycosis [12-14] and nail psoriasis [15] can cause embarrassment, stigmatization, and other psychosocial problems. Patients would therefore benefit from treatments that produce rapid cosmetic improvements in affected nails. Early improvements in the appearance of nails affected by onychomycosis and psoriasis were seen in clinical investigations of marketed treatments containing a combination of propylene glycol, urea, and lactic acid. Such treatments include versions of K101 which differ slightly in terms of their composition. In one early study, improvements were seen in 21 of 23 onychomycosis patients treated for 2-6 months with a test solution containing propylene glycol, urea, and lactic acid [16]. A subsequent randomized controlled trial investigated K101 in 493 patients with distal subungual onychomycosis. The proportion of patients who were mycologically cured after 24 weeks of treatment (plus a 2-week washout) was higher for K101 than for a placebo preparation (27.2 vs. $10.4 \%)$. In addition, more patients receiving K101 judged that their condition had improved, with statistically significant differences versus placebo from 2 weeks until the end of the study at 26 weeks [17]. In a separate study, nail psoriasis patients treated for 16 weeks with a lotion containing propylene glycol and urea showed significant improvements in nail pitting, subungual keratosis, and onycholysis [18]. Other more recent clinical in-

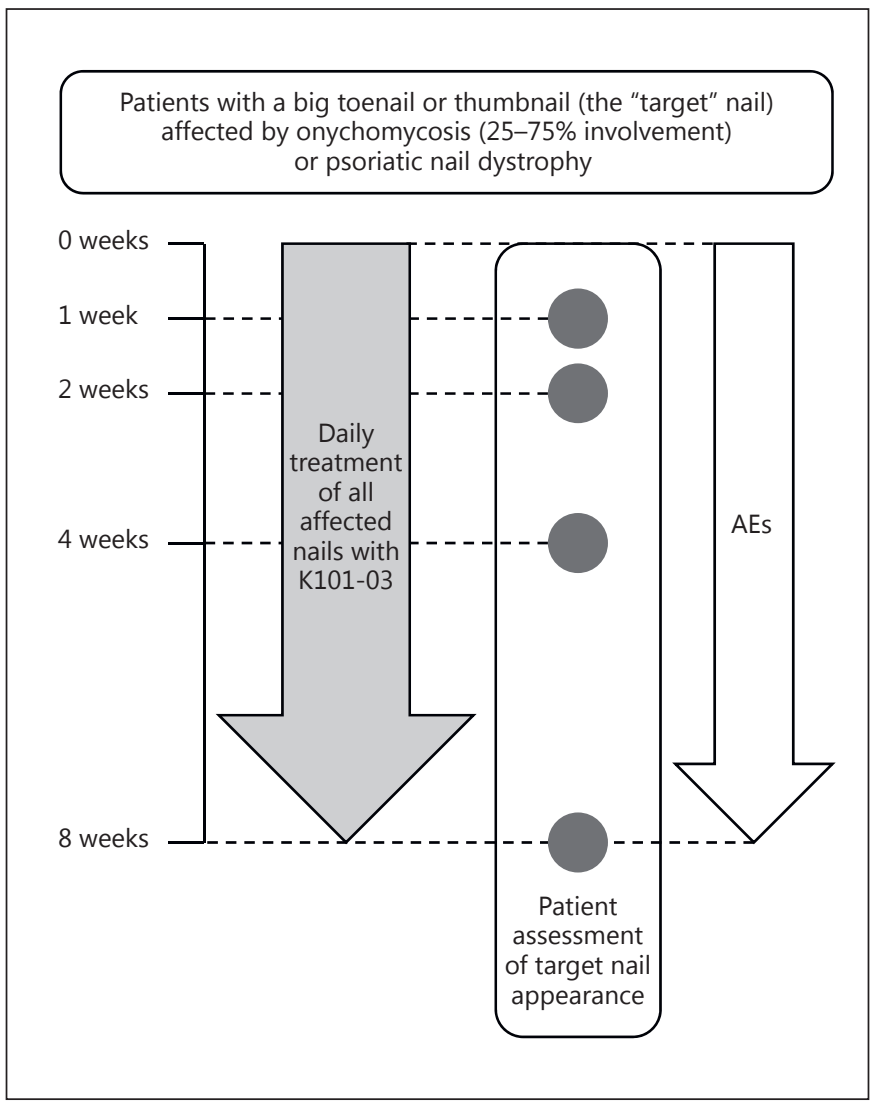

Fig. 1. Flowchart of the Patients and Methods.

vestigations showed rapid improvements in nail appearance and few treatment-related adverse events (AEs) in onychomycosis patients treated with K101 [19] or Kerasal Nail ${ }^{\mathrm{TM}}$ (K101-05) [20].

As outlined above, treatments containing propylene glycol, urea, and lactic acid have shown good efficacy and tolerability in clinical investigations. K101-03 is a marketed EDTA-containing derivate of K101 in which some of the propylene glycol has been replaced with glycerol to increase viscosity and thus make application easier. The present study was conducted to investigate the efficacy and safety of K101-03 when used to treat patients with onychomycosis and/or nail psoriasis for 8 weeks.

\section{Patients and Methods}

For further details, see the supplementary material (for all online suppl. material, see www.karger.com/doi/10.1159/000478257) (Fig. 1). 
Table 1. Demographics and baseline characteristics (safety set)

\begin{tabular}{|c|c|c|c|}
\hline & $\begin{array}{l}\text { Onychomycosis } \\
(n=72)\end{array}$ & $\begin{array}{l}\text { Psoriasis }^{\mathrm{a}} \\
(n=35)\end{array}$ & $\begin{array}{l}\text { All patients } \\
(n=107)\end{array}$ \\
\hline \multicolumn{4}{|l|}{ Age, years } \\
\hline Mean \pm SD & $59.8 \pm 13.75$ & $56.7 \pm 13.36$ & $58.8 \pm 13.64$ \\
\hline Median & 60 & 59 & 59 \\
\hline Range & $23-88$ & $25-82$ & $23-88$ \\
\hline \multicolumn{4}{|l|}{ Sex, $n(\%)$} \\
\hline Female & $43(59.7)$ & $23(65.7)$ & $66(61.7)$ \\
\hline Male & $29(40.3)$ & $12(34.3)$ & $41(38.3)$ \\
\hline \multicolumn{4}{|l|}{ Race, $n(\%)$} \\
\hline White/Caucasian & $72(100.0)$ & $33(94.3)$ & $105(98.1)$ \\
\hline Other & $0(0.0)$ & $2(5.7)$ & $2(1.9)$ \\
\hline
\end{tabular}

a Including 1 patient who also had onychomycosis.

\section{Results}

Patient disposition is shown in Figure 2. A total of 130 subjects were screened, and 108 of them (72 with onychomycosis alone, 35 with nail psoriasis alone, and 1 with both onychomycosis and nail psoriasis who was included in the nail psoriasis subgroup) were enrolled in the study. The first patient first applied K101-03 on May 17, 2016, and the last patient's last visit was on November 8, 2016. One patient with psoriasis did not receive the study treatment and was thus excluded from the safety set, which comprised 107 patients. Four patients ( 3 with onychomycosis and 1 with psoriasis) did not perform a postbaseline efficacy assessment of the target nail and were therefore excluded from the full analysis set $(n=103)$. Six patients (5 with onychomycosis and 1 with psoriasis) were each excluded from the per-protocol set $(n=97)$ because of both treatment compliance $<80 \%$ and failure to do an efficacy assessment at week 8 . Of the 107 patients who were treated with K101-03, 97 (90.7\%) completed the study.

Mean treatment compliance for the 107 treated patients was $96.1 \%$ (standard deviation [SD] 16.28, median 100 , range 12.5-100). Mean compliance for the onychomycosis subgroup was $94.9 \%$.

The median age of participants was 59 years (range 23-88), and 66 (61.7\%) of them were female (Table 1). All but 2 of the participants were White/Caucasian.

At 8 weeks, $92.2 \%$ of patients $(95 / 103)$ reported at least some visible improvement in the target nail (95\% confidence interval [CI] 87.06-97.40) (Table 2). The percentage of patients in the onychomycosis subgroup who reported at least some visible improvement in the target nail

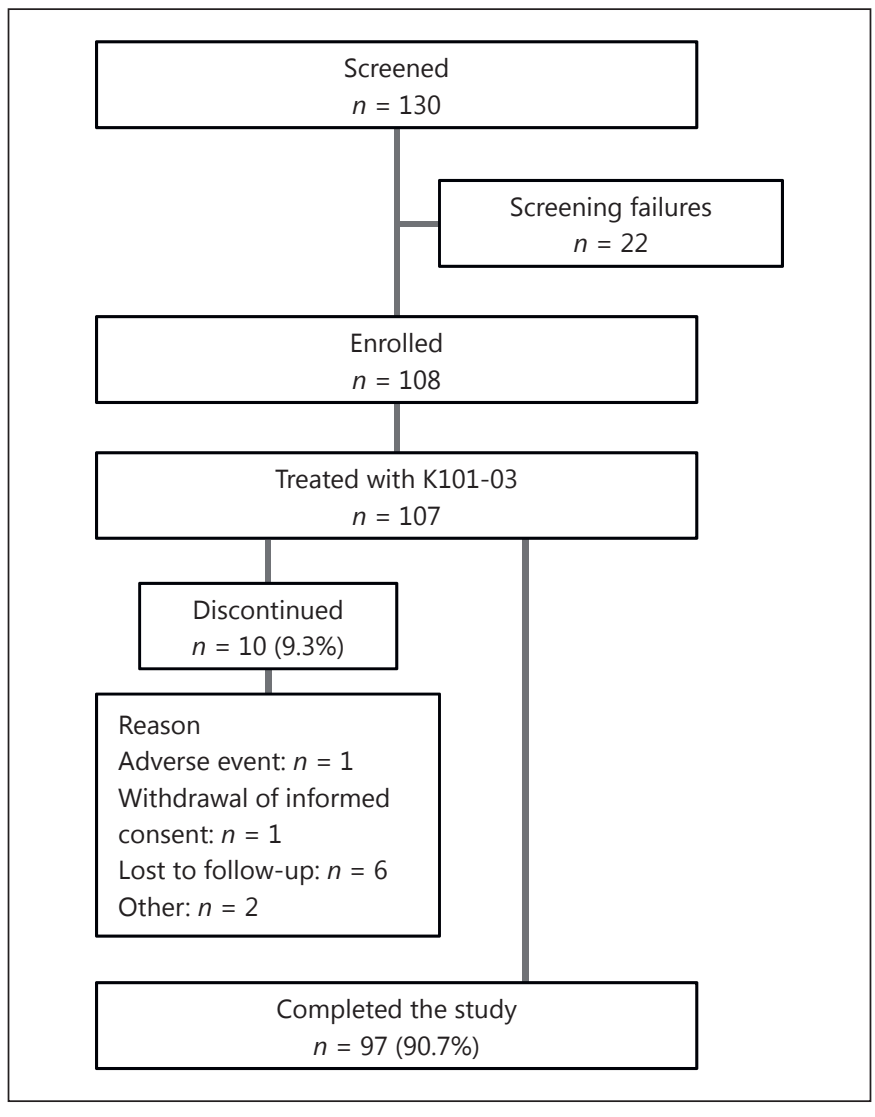

Fig. 2. Patient disposition.

at 8 weeks was $91.3 \%$ (95\% CI 84.66-97.95). Similar results were obtained for the per-protocol set (data not shown).

Table 3 shows global assessment scale scores for target nails in patients with onychomycosis alone after treatment with K101-03 for 1, 2, and 4 weeks. Fifty-four patients (78.3\%, 95\% CI 68.53-87.99) reported at least some improvement in target nail appearance after only 1 week of K101-03 treatment. The proportion of patients who reported at least some improvement in the target nail was $89.9 \%$ (95\% CI 82.73-96.98) at 2 weeks and 94.2\% (95\% CI 88.69-99.72) at 4 weeks. Approximately half of the patients reported a clear or very good visible improvement in the target nail after 4 weeks of K101-03 treatment (Table 3).

Figure 3 shows examples of onychomycosis-affected nails that underwent visible improvements during 8 weeks of treatment with K101-03.

Table 4 shows scores for individual target nail attributes in patients with onychomycosis alone during and 
Table 2. Global assessment scale scores at 8 weeks (full analysis set, last observation carried forward)

\begin{tabular}{|c|c|c|c|c|c|c|}
\hline \multirow[t]{2}{*}{$\begin{array}{l}\text { Appearance of target nail } \\
\text { compared to baseline }\end{array}$} & \multicolumn{2}{|c|}{$\begin{array}{l}\text { Onychomycosis } \\
(n=69)\end{array}$} & \multicolumn{2}{|c|}{$\begin{array}{l}\text { Psoriasis }^{\mathrm{a}} \\
(n=34)\end{array}$} & \multicolumn{2}{|c|}{$\begin{array}{l}\text { All patients } \\
(n=103)\end{array}$} \\
\hline & $n$ & $\%$ & $n$ & $\%$ & $n$ & $\%$ \\
\hline 1 No improvement & 6 & 8.7 & 2 & 5.9 & 8 & 7.8 \\
\hline 2 Some improvement & 30 & 43.5 & 15 & 44.1 & 45 & 43.7 \\
\hline 3 Clear improvement & 24 & 34.8 & 12 & 35.3 & 36 & 35.0 \\
\hline 4 Very good improvement & 9 & 13.0 & 5 & 14.7 & 14 & 13.6 \\
\hline$\geq 2$ At least some improvement & 63 & 91.3 & 32 & 94.1 & 95 & 92.2 \\
\hline
\end{tabular}

Percentage values are correct to 1 decimal place. The values for all patients add up to 100.1 (rather than 100) because of rounding. ${ }^{a}$ Including 1 patient who also had onychomycosis.

after 8 weeks of treatment with K101-03. After the first week of treatment, the attribute that was improved in the highest proportion of patients was discoloration (55.1\%), followed by softness (50.7) and brittleness (40.6\%). After 4 weeks of treatment, discoloration, thickening, and softness each showed improvements in two thirds of patients; $53.0 \%$ of patients reported at least some improvement in brittleness. After 8 weeks of treatment, the attributes that were most frequently improved were thickening $(78.1 \%)$ and softness (76.6\%) (Table 4).

Two of the 72 patients in the onychomycosis group reported 1 or more AEs. One of the patients reported gout, graded as mild and judged to be unrelated to K10103. The other patient reported 2 serious AEs: head injury and rib fracture. The serious AEs were both graded as severe and judged to be unrelated to K101-03. The patient withdrew from the study 12 days after the serious AEs had been reported. One patient in the psoriasis group reported 2 AEs: onychoclasis and skin irritation. Both AEs were graded as moderate; neither of them was judged to be related to K101-03.

\section{Discussion}

As with previous studies of propylene glycol-urea-lactic acid preparations $[19,20]$, K101-03 produced rapid improvements in the patients included in the present study. After 8 weeks of treatment, $92.2 \%$ of patients reported improvement in their target nail. Moreover, $78.3 \%$ of onychomycosis patients reported improvements after the first week of treatment and $89.9 \%$ after 2 weeks. These results confirm previous findings for K101 and Kerasal Nail. In an 8-week study of K101 in 75 onychomycosis
Table 3. Global assessment scale scores at 1,2 , and 4 weeks for patients with onychomycosis (full analysis set, $n=69$, last observation carried forward)

\begin{tabular}{|c|c|c|c|c|c|c|}
\hline \multirow{2}{*}{$\begin{array}{l}\text { Appearance of target } \\
\text { nail compared to baseline }\end{array}$} & \multicolumn{2}{|c|}{1 week } & \multicolumn{2}{|c|}{2 weeks } & \multicolumn{2}{|c|}{4 weeks } \\
\hline & $n$ & $\%$ & $n$ & $\%$ & $n$ & $\%$ \\
\hline 1 No imp & 15 & 21.7 & 7 & 10.1 & 4 & 5.8 \\
\hline 2 Some improvement & 48 & 69.6 & 42 & 60.9 & 30 & 43.5 \\
\hline 3 Clear improvement & 5 & 7.2 & 18 & 26.1 & 32 & 46.4 \\
\hline $\begin{array}{l}4 \text { Very good improvement } \\
\geq 2 \text { At least some }\end{array}$ & 1 & 1.4 & 2 & 2.9 & 3 & 4.3 \\
\hline improvement & 54 & 78.3 & 62 & 89.9 & 65 & 94.2 \\
\hline
\end{tabular}

Percentage values are correct to 1 decimal place. The values for 1 week add up to 99.9 (rather than 100) because of rounding.

Table 4. Proportions of onychomycosis patients who reported improvements in target nail attributes during treatment with K10103 (full analysis set)

\begin{tabular}{|c|c|c|c|c|c|c|c|c|}
\hline \multirow[t]{2}{*}{$\begin{array}{l}\text { Target nail } \\
\text { attribute }\end{array}$} & \multicolumn{2}{|c|}{$\begin{array}{l}1 \text { week } \\
(n=69)\end{array}$} & \multicolumn{2}{|c|}{$\begin{array}{l}2 \text { weeks } \\
(n=67)\end{array}$} & \multicolumn{2}{|c|}{$\begin{array}{l}4 \text { weeks } \\
(n=66)\end{array}$} & \multicolumn{2}{|c|}{$\begin{array}{l}8 \text { weeks } \\
(n=64)\end{array}$} \\
\hline & $n$ & $\%$ & $n$ & $\%$ & $n$ & $\%$ & $n$ & $\%$ \\
\hline Thickening & 23 & 33.3 & 32 & 47.8 & 44 & 66.7 & 50 & 78.1 \\
\hline Discoloration & 38 & 55.1 & 48 & 71.6 & 44 & 66.7 & 42 & 65.6 \\
\hline Brittleness & 28 & 40.6 & 33 & 49.3 & 35 & 53.0 & 40 & 62.5 \\
\hline Softness & 35 & 50.7 & 43 & 64.2 & 44 & 66.7 & 49 & 76.6 \\
\hline
\end{tabular}

patients, $77 \%$ of patients reported at least some improvement in an affected nail at 2 weeks and $88 \%$ at 4 weeks [19]. A more recent study of Kerasal Nail in onychomycosis showed improvements in $65 \%$ of patients after 




0 weeks

1 week

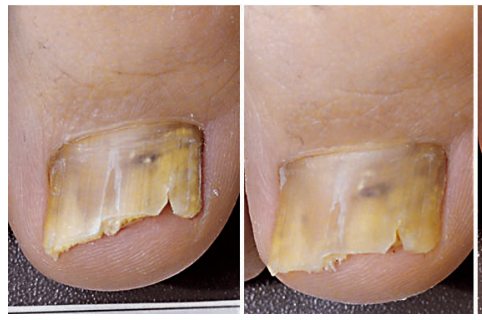

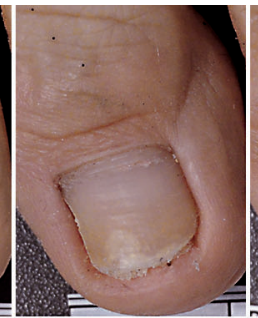

2 weeks

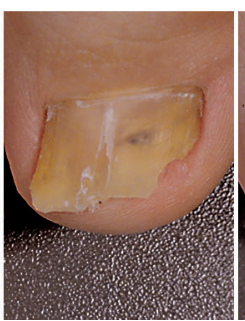

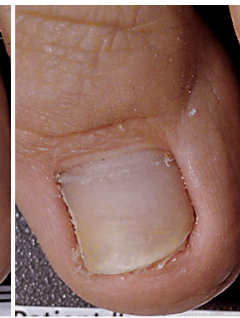

4 weeks



mycosise improvements in an onycho treatment with K101-03.

1 week of treatment and in $82 \%$ of patients after 2 weeks [20]. Like K101 [19] and Kerasal Nail [20], K101-03 rapidly improved the physical attributes of onychomycosisaffected nails, with discoloration in particular showing early improvements in the majority of patients.

Patients with onychomycosis [12-14] and nail psoriasis [15] often feel embarrassed or stigmatized because of their disease. Such feelings are not unfounded, as shown by a recent online survey [14], in which many respondents expressed reluctance to spend time with or be placed next to onychomycosis patients. The present study indicates that K101-03 rapidly improves the nails of patients with onychomycosis and/or nail psoriasis. It may thus help to alleviate embarrassment and stigmatization in patients with these conditions.

There were no treatment-related AEs in the present study. The only treatment-related AEs in previous studies of short-term K101 and Kerasal Nail treatment were 2 cases of administration site pain in patients treated with Kerasal Nail [19, 20]. K101, K101-03, and Kerasal Nail are each supplied in a plastic tube with a silicone tip designed to facilitate precise application to affected nails and to minimize potential irritant effects due to excessive skin contact. The excellent safety profiles of K101-03 and similar products are in marked contrast to the potential toxicity associated with systemic antifungal treatments for onychomycosis [5].

Mean overall treatment compliance was $96.1 \%$. Treatment compliance for K101 [19] and Kerasal Nail [20] was similarly high (>95\%) in previous clinical investigations. This suggests that formulations containing propylene glycol, urea, and lactic acid are effective, well tolerated, and patient friendly.

The present study has some limitations. These include the absence of a control group and the consequent lack of blinding. The fact that the participants knew they were receiving an active treatment may have affected the scoring of their nails and is particularly important considering the subjective nature of the study's efficacy variables. Also, the participants were all recruited in a single country: Italy. Given that $98 \%$ of participants were White/ Caucasian, they may not properly represent the patient populations of Europe. However, they were recruited at 8 sites representing different regions of Italy. Furthermore, the above-mentioned study of Kerasal Nail yielded similar results in an Asian population [20], which suggests that the effects of propylene glycol-urea-lactic acid preparations are not ethnicity dependent.

In conclusion, K101-03 was well tolerated and rapidly improved the cosmetic appearance of disease-affected nails, with over three quarters of onychomycosis patients reporting improvements after the first week of treatment. Importantly, efficacy was good in 2 fundamentally different diseases, indicating that the effects of K101-03 are at least partly independent of disease etiology.

\section{Key Message}

Patients with onychomycosis and/or nail psoriasis report improvements after just 1 week of K101-03 treatment. 


\section{Acknowledgments}

The authors thank the patients and staff who participated in the study. In particular, the authors thank the study's co-investigators for their invaluable contributions: Prof. Luca Bianchi of University Hospital Tor Vergata, Rome; Prof. Giuseppe Argenziano of the University of Naples; Prof. Anna Virgili and Prof. Monica Corazza of Hospital S. Anna, Ferrara; Prof. Marina Venturini of Civil Hospital, Brescia; Prof. Giuseppe Micali of the University Hospital of Catania; Prof. Ketty Peris of Università Cattolica del Sacro Cuore, Rome; and Prof. Manuela Papini of S. Maria Hospital, Terni. The authors also acknowledge Stephen Gilliver of TFS AB for medical writing services, paid for by Moberg Pharma AB. Moberg Pharma $\mathrm{AB}$ funded the study and supplied the study product. Monitoring, data management, statistical analysis, and reporting were outsourced to a contract resource organization.

\section{Statement of Ethics}

The clinical investigation plan (dated February 16, 2016) was approved, in writing, by the independent ethics committees for the different study sites between April 14, 2016, and June 28, 2016, before the first patient was enrolled at the respective sites. The study was conducted in accordance with the Declaration of Helsinki, ICH E6 Good Clinical Practice, ISO 14155:2011, MEDDEV guidelines, and Italian regulations.

\section{Disclosure Statement}

B.M.P. and M.S. work at Università di Bologna, which received a grant for performing the study. They have no other funding arrangements or conflicts of interest relating to this research. A.T. is an employee of Moberg Pharma AB, which manufactures K101-03 and is involved in its marketing.

\section{References}

1 Ghannoum M, Isham N: Fungal nail infections (onychomycosis): a never-ending story? PLoS Pathog 2014;10:e1004105.

2 Haneke E, Roseeuw D: The scope of onychomycosis: epidemiology and clinical features. Int J Dermatol 1999;38(suppl 2):7-12.

3 Tosti A, Elewski BE: Onychomycosis: practical approaches to minimize relapse and recurrence. Skin Appendage Disord 2016;2:83-87.

4 Milobratović D, Janković S, Vukičević J, Marinković J, Janković J, Railić Z: Quality of life in patients with toenail onychomycosis. Mycoses 2013;56:543-551.

5 Gupta AK, Shear NH: A risk-benefit assessment of the newer oral antifungal agents used to treat onychomycosis. Drug Saf 2000;22: 33-52.

6 Lauharanta J: Comparative efficacy and safety of amorolfine nail lacquer $2 \%$ versus $5 \%$ once weekly. Clin Exp Dermatol 1992;17(suppl 1):41-43.

7 Alley MRK, Baker SJ, Beutner KR, Plattner J: Recent progress on the topical therapy of onychomycosis. Expert Opin Investig Drugs 2007;16:157-167.

8 Scher RK, Baran R: Onychomycosis in clinical practice: factors contributing to recurrence. Br J Dermatol 2003;149(suppl 65):5-9.
9 Crowley JJ, Weinberg JM, Wu JJ, Robertson AD, Van Voorhees AS; National Psoriasis Foundation: Treatment of nail psoriasis: best practice recommendations from the Medical Board of the National Psoriasis Foundation. JAMA Dermatol 2015;151:87-94.

10 Klaassen KMG, van de Kerkhof PCM, Pasch MC: Nail psoriasis, the unknown burden of disease. J Eur Acad Dermatol Venereol 2014; 28:1690-1695.

11 de Jong EM, Seegers BA, Gulinck MK, Boezeman JB, van de Kerkhof PC: Psoriasis of the nails associated with disability in a large number of patients: results of a recent interview with 1,728 patients. Dermatology 1996;193: 300-303.

12 Drake LA, Scher RK, Smith EB, Faich GA, Smith SL, Hong JJ, Stiller MJ: Effect of onychomycosis on quality of life. J Am Acad Dermatol 1998;38:702-704.

13 Chacon A, Franca K, Fernandez A, Nouri K: Psychosocial impact of onychomycosis: a review. Int J Dermatol 2013;52:1300-1307.

14 Chan HH, Wong ET, Yeung CK: Psychosocial perception of adults with onychomycosis: a blinded, controlled comparison of 1,017 adult Hong Kong residents with or without onychomycosis. Biopsychosoc Med 2014;8:15.
15 Hawro M, Maurer M, Weller K, Maleszka R, Zalewska-Janowska A, Kaszuba A, GerliczKowalczuk Z, Hawro T: Lesions on the back of hands and female gender predispose to stigmatization in patients with psoriasis. J Am Acad Dermatol 2017;76:648-654.e2.

16 Faergemann J, Swanbeck G: Treatment of onychomycosis with a propylene glycol-urealactic acid solution. Mycoses 1989;32:536540

17 Emtestam L, Kaaman T, Rensfeldt K: Treatment of distal subungual onychomycosis with a topical preparation of urea, propylene glycol and lactic acid: results of a 24 -week, doubleblind, placebo-controlled study. Mycoses 2012;55:532-540.

18 de Jong EM, Menke HE, van Praag MC, van de Kerkhof PC: Dystrophic psoriatic fingernails treated with $1 \% 5$-fluorouracil in a nail penetration-enhancing vehicle: a doubleblind study. Dermatology 1999;199:313-318.

19 Faergemann J, Gullstrand S, Rensfeldt K: Early and visible improvements after application of K101 in the appearance of nails discoloured and deformed by onychomycosis. J Cosmet Dermatol Sci Appl 2011;1:59-63.

20 Pan JY, Tan CL, Toft A: Rapid visible improvements in onychomycosis: an open-label clinical investigation of Kerasal Nail ${ }^{\mathrm{TM}}$. J Cosmet Dermatol Sci Appl 2017;7:57-66. 